Thermal Conductivity of HiNS

B. D. Faubion

DEVELOPMENT DIVISION

MARCH 1976

P. O. NO. 03-5534

Eor

Sandia Laboratories

ATbuquerque, New Mexico

政 P. 0. $30 x$ sy

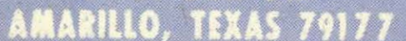

$203-835 \cdot 1501$

aporased tor the

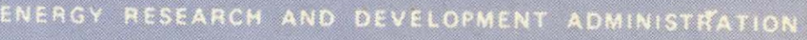
4neter:

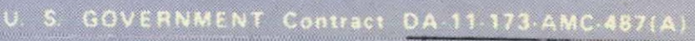




\section{DISCLAIMER}

This report was prepared as an account of work sponsored by an agency of the United States Government. Neither the United States Government nor any agency Thereof, nor any of their employees, makes any warranty, express or implied, or assumes any legal liability or responsibility for the accuracy, completeness, or usefulness of any information, apparatus, product, or process disclosed, or represents that its use would not infringe privately owned rights. Reference herein to any specific commercial product, process, or service by trade name, trademark, manufacturer, or otherwise does not necessarily constitute or imply its endorsement, recommendation, or favoring by the United States Government or any agency thereof. The views and opinions of authors expressed herein do not necessarily state or reflect those of the United States Government or any agency thereof. 


\section{DISCLAIMER}

Portions of this document may be illegible in electronic image products. Images are produced from the best available original document. 


\section{NOTICE}

This report was prepared as an account of work sponsored by the United States Government. Neither the United States nor the United States Energy Research and Development Administration, nor their employees, nor any of their contractors, subcontractors, or their employees, makes any warranty, express or implied, or assumes any legal liability or responsibility for the accuracy, completeness or usefulness of any information, apparatus, product or process disclosed, or represents that its use would not infringe privátely-uwıed riylıls. 


\title{
THERMAL CONDUCTIVITY OF HNS
}

March 1976

P. O. No. 03-5534

$-1-$

mis report was prepared as an account of work

sponsoled by the United staies Government. Nelles

spe United stales not the Unistation, nor any of Resen and Develaparens $A$ dn of theis cantrestorn their employees, not any croployets. makes any

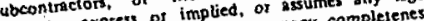
wartanty, express of in for the sccuracy, complesent

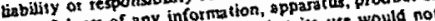

of userthes of any in repras

process diactosed, ou sed rights.

\author{
B. D. Faubion \\ DEVELOPMENT DIVISION
}

\author{
P. O. No. $03-5534$
}

DISTREMTION OF THIS DCUMENT IS UMLMITED 


\section{ABSTRACT}

The thermal conductivity of HNS I and two samples of HNS II was determined at 222, 293, 347 and $394 \mathrm{~K}$. The thermal diffusivity of pellets of each HNS lot pressed to three densities was measured using the pulse heating method. The thermal conductivity was calculated for each pellet from the thermal diffusivity, density and the specific heat. The specific heat for each HNS sample was measured at each temperature using the DSC method.

\section{INTRODUCTION}

The pulse or flash method has been used for measuring the thermal diffusivity of a variety of materials $(1,2,3,4,5)$. There have, however, been no reports in the literature of the application of this technique to the measurement of the thermal diffusivity of explosives. Calculation of the thermal conductivity from the thermal diffusivity measured by this method is faster and requires considerably less sample than the sta'ndard guarded hot plate technique (ASTM C17.7) for measuring thermal conductivity. When working with explosives in the laboratory it is desirable to use as small a sample as is convenient in order. to minimize the hazards.

The principles of the pulse method have been covered in detail in the references cited above; therefore, only a brief outline of the procedure will be given here. One surface of a thin, disc-shaped specimen is heated with a short pulse of radiant energy, usually from a flash lamp or laser. The temperature of the opposite face is recorded as a function of time: If the experiment were carried out in such a way that the heat flow is one dimensional, the material properties are independent of temperature, the heat pulse is unfform over the sample surface arid is instantaneous and there is no heat loss from the surfaces, then the thermal diffusivity $(\alpha)$ in cgs units is given by:

$$
=\frac{1.37 \ell^{2}}{\pi^{2} t_{\frac{1}{2}}}
$$

where $\ell$ is the sample thickness in $\mathrm{cm}$ and $t_{\frac{1}{2}}$ is the time in seconds required for the temperature of the back surface to reach half of the maximum value. In most practical applications of this method the conditions above are usually not rigorously met. Even so, it is still possible to obtain reliable values for the thermal diffusivity. Corrections for finite pulse widtli and radiation or convection heat loss at the surfaces have been proposed $(6,7,8)$.

\section{EXPERIMENTAL PROCEDURE}

The experimental apparatus for measuring the thermal diffusivity by the flash method consisted of a test chamber with a thermostated sample holder, a laser, and temperature recorder. A block diagram of the assembiy is shown in Fig. 1 . 
Details of the test chamber and sample holder are shown in Fig. 2 . The sample holder was capable of being cooled to approximately $-60 \mathrm{C}$ by cold nitrogen gas flowing through the outer chamber. The nitrogen was chilled by passing it through a copper coil immersed in liquid nitrogen. A heater coil in the sample block was used to adjust the temperature up to approximately $180 \mathrm{C}$. The temperature was controlled using a Fisher Model 22 Proportional Temperature Controller with a thermistor probe inserted in the block.

A Spectra Physics Model 164 Argon ion laser was used as the source of radiant energy. This laser had a continuous output of approximately $800 \mathrm{mw}$. A photographic shutter was used to expose the sample to short pulses of the laser beam. A $20 x$ microscope objective was used to expand the laser beam to just cover the front surface of the sample.

The rear surface temperature of the sample was monitored with one junction of a differential chromel-alumel thermocouple. The other junction was inserted in the sample holder. Thermal contact with the sample was insured by using a thermal conducting paste ${ }^{\text {, which had }}$ a thermal conductivity of $17 \times 10^{-14} \mathrm{cal} \mathrm{cm}^{-1} \mathrm{sec}^{-1} \mathrm{deg}^{-1}$. The output of the differential thermocouple was first amplified with a DC Microvolt Amplifier ${ }^{b}$ and then recorded with a Mosley Model 2D-2 X-Y Recorder. The $X$-axis of the recorder was operated in the time sweep mode at two seconds per inch.

The specific heat of each sample was determined using the standard procedure for the Perkin-Elmer'Differential Scanning Calorimeter Model DSC I $(9)$.

One sample of HNS I (Pantex Lot 5-315-XHNS-12) and two samples of HNS II (Pantex Lot 5178-137-01 and Ensign Bickford Lot ENB-5737-02) were used in this study. Two pellets of each sample were pressed in a $1.27 \mathrm{~cm}$ diameter die on the Dead Weight Press to three different densities. One pellet at each density was approximately $0.13 \mathrm{~cm}$ thick and the other approximately $0.16 \mathrm{~cm}$ thick. This sample configuration can be treated as a one dimensional system with respect to heat transfer along the axis and since the diameter is 8 to 9 times greater than the thickness, edge loss effects should be insignificant.

\section{RESUIITS AND DISCUSSION}

The specific heat for each sample of HNS was measured at $222,293,347$, 394 and $533 \mathrm{~K}$. The results are listed in Table I. These values are the average of two runs which were within $\pm 2 \%$ of the average. A plot of

\footnotetext{
Thermacote Thermal Joint Compounds, Thermalzoy Co., Dalzas, Texas.

$b_{\text {Leeds }}$ and Northrup, Model 9835-B.
} 
the specific heat as a function of absolute temperature is shown in Fig. 3 . These values along with the measured densities of each sample were used in determining the thermal conductivity $(\lambda)$ from the thermal diffusivity $(\alpha)$ according to the equation

$$
\lambda=\mathrm{C}_{\rho} \alpha
$$

The thermal diffusivity for each sample of HNS at three different densities and two sample thicknesses at each density was measured at $222,293,347$ and $394 \mathrm{~K}$. Fig. 4 illustrates a typical recording of the rear surface temperature rise as a function of time after the front surface of the pellet had been exposed to the laser beam for 0.5 . seconds. Under ideal conditions the thermal diffusivity can be calculated using Equation 1 by determining the time at which the temperature reached one-half of the maximum value $\left(t_{\frac{1}{2}}\right)$.

The temperature-time curve in Fig: 4 does not correspond to the ideal case. In order to obtain good thermal diffusivity values it is necessary to analyze the results taking into account deviations from ideality. Correction for finite pulse-time and heat-loss effects can be accomplished using the tables in Reference 8 . These corrections were applied to all of the experimental curves. The heat-loss parameter $L$ was determined from Table III of Reference 8 for the case where the front and back surface heat-loss parameters are equal by using the nondimensional temperature $\left(T / T_{\max }\right)$ at the point $4 t_{\frac{1}{2}}$ on the experimental temperature-time curve. The diffusivity was then calculated from $t_{\frac{1}{2}}$ and the value for $t / t_{c}$ in Table II of Reference 8 corresponding to the established heat-loss parameter by the equation

$$
\alpha_{0}=\left(t / t_{c}\right) \frac{l^{2}}{t_{\frac{1}{2}}}
$$

where $\ell$ is the thickness of the sample. Correction for finite pulse time was accomplished using Table I of Reference 8. A trianglar pulse shape with the maximum at one-half pulse time $T$ was assumed and the value for $\left(\alpha / \alpha_{0}\right)$ corresponding to a value for $\left(\tau / t_{1 / 2}\right)$ was determined. The corrected thermal diffusivity was then given by muttiplying the diffusivity given by Equation 3 by the ratio $\left(\alpha / \alpha_{0}\right)$.

The corrected thermal diffusivity was then used to calculate the. thermal conductivity for each sample.

The results are tabulated in Tables II through IV and are graphically illustrated in Figs. 5 through 13. Each value is the average of three runs. The sigma ranged from approximately $\pm 3 \%$ at room temperature to $\pm 10 \%$ at the temperature extremes.

All of the runs show a slight temperature dependency. In general, the thermal conductivity increases with increasing temperature; however, several of the runs show a slight negative curvature. 
Since the thermal conductivity of HNS has not been measured by other methods there was no basis for judging the results by the flash method.

The measured values are less than half of the "reasonable guess" reported by Rogers (10). 
Table I. Specific Heat of HNS

\begin{tabular}{cccc}
$\begin{array}{c}\text { Temp. } \\
(K)\end{array}$ & $\frac{C\left(c a 1 g^{-1} \mathrm{deg}^{-1}\right)}{H N S I I}$ & $\begin{array}{c}\text { HNS II } \\
\text { (Ensign } \\
\text { Brickford) }\end{array}$ \\
\hline 222 & $\frac{\text { HNS I }}{\text { (Pantex) }}$ & 0.184 \\
293 & 0.174 & 0.189 & 0.227 \\
347 & 0.235 & 0.225 & 0.256 \\
394 & 0.266 & 0.256 & 0.289 \\
533 & 0.302 & 0.283 & 0.372
\end{tabular}

Table II. Thermal Conductivity of HNS I

\begin{tabular}{|c|c|c|c|c|c|c|c|}
\hline $\begin{array}{c}\text { Temp. } \\
(K)\end{array}$ & 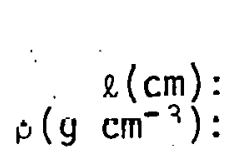 & $\begin{array}{l}0.1359 \\
1.5150 \\
\end{array}$ & $\begin{array}{r}\quad(\lambda \\
0.1582 \\
1.4880 \\
\end{array}$ & $\begin{array}{l}\left.10^{4}\right) \text {. } \\
0.1382 \\
1.5910 \\
\end{array}$ & $\begin{array}{c}m=1 \cdot s c c \\
0.1621 \\
1.5890\end{array}$ & $\begin{array}{l}\frac{\mathrm{deg}^{-1}}{0.1359} \\
1.6450\end{array}$ & $\begin{array}{l}0.1 .669 \\
1.6460 \\
\end{array}$ \\
\hline 222 & & 0.96 & 1.62 & 1.65 & 1.82 & 1.45 & 1.82 \\
\hline 293 & & 1.43 & 1.36 & 1.60 & 1.90 & 1.75 & 2.04 \\
\hline 347 & & 1.47 & 1.50 & 1.89 & 2.31 & 2.27 & 2.34 \\
\hline 394 & & 1.65 & 1.37 & 2.07 & 2.14 & 2.11 & 2.26 \\
\hline
\end{tabular}


Table III. Thermal Conductivity of Pantex HNS II

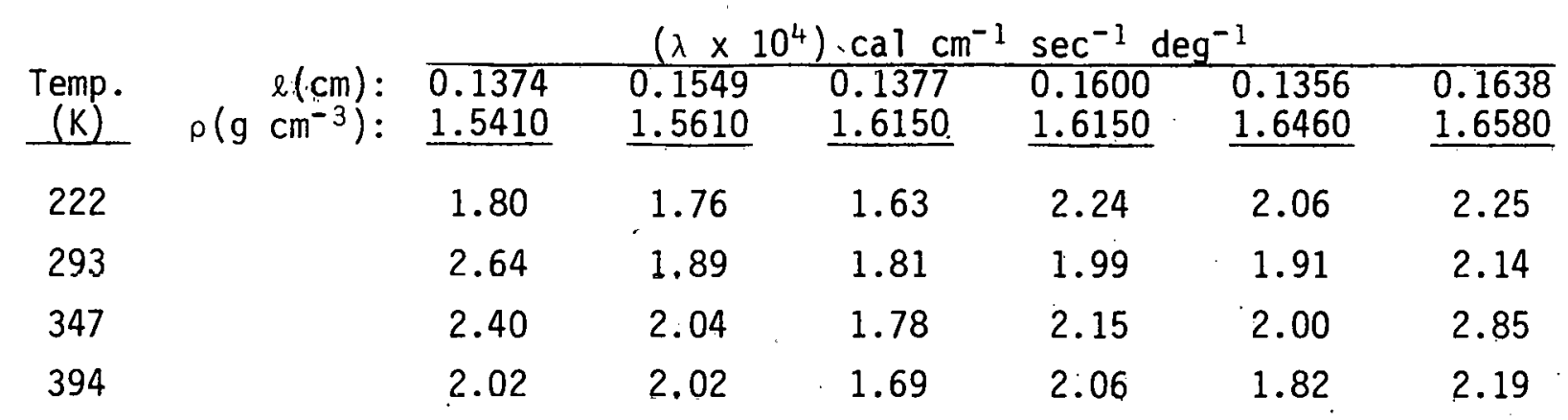

Table IV. Thermal Conductivity of Ensign Bickford HNS II

\begin{tabular}{|c|c|c|c|c|c|c|c|}
\hline $\begin{array}{l}\text { Temp. } \\
(\mathrm{K})\end{array}$ & 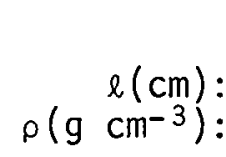 & $\begin{array}{l}0.1318 \\
1.5670 \\
\end{array}$ & $\begin{array}{c}(\lambda \times \\
0.1537 \\
1.5650 \\
\end{array}$ & $\begin{array}{r}1 \mathrm{cal} \mathrm{cn} \\
0.1372 \\
1.5840 \\
\end{array}$ & $\begin{array}{l}\mathrm{sec}^{-1} \\
0.1588 \\
1.6120\end{array}$ & $\begin{array}{l}-1 \\
0.1354 \\
1.6590 \\
\end{array}$ & $\begin{array}{l}0.1638 \\
1.6740 \\
\end{array}$ \\
\hline 222 & & 1.54 & 2.30 & 1.87 & 1.63 & 1.38 & 1.78 \\
\hline 293 & & 1.60 & 2.25 & 1.84 & 2.13 & 1.80 & 2.19 \\
\hline 347 & & Pellet & 2.49 & 1.83 & 2.05 & 2.06 & 1.92 \\
\hline 394 & & Shattered & 2.36 & 1.85 & 2.33 & 1.93 & 2.52 \\
\hline
\end{tabular}




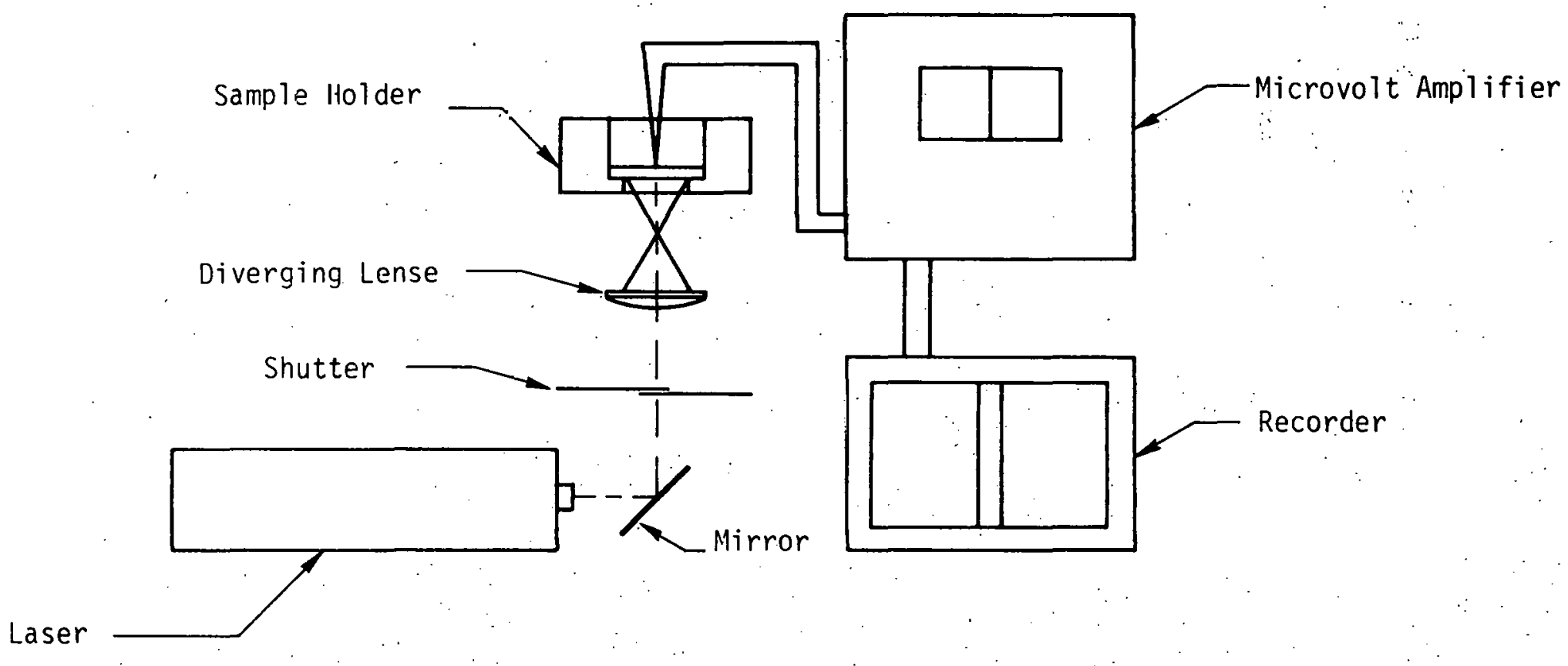

Fig. 1. Block Diagram of flash Thermal Diffusivity Apparatus 

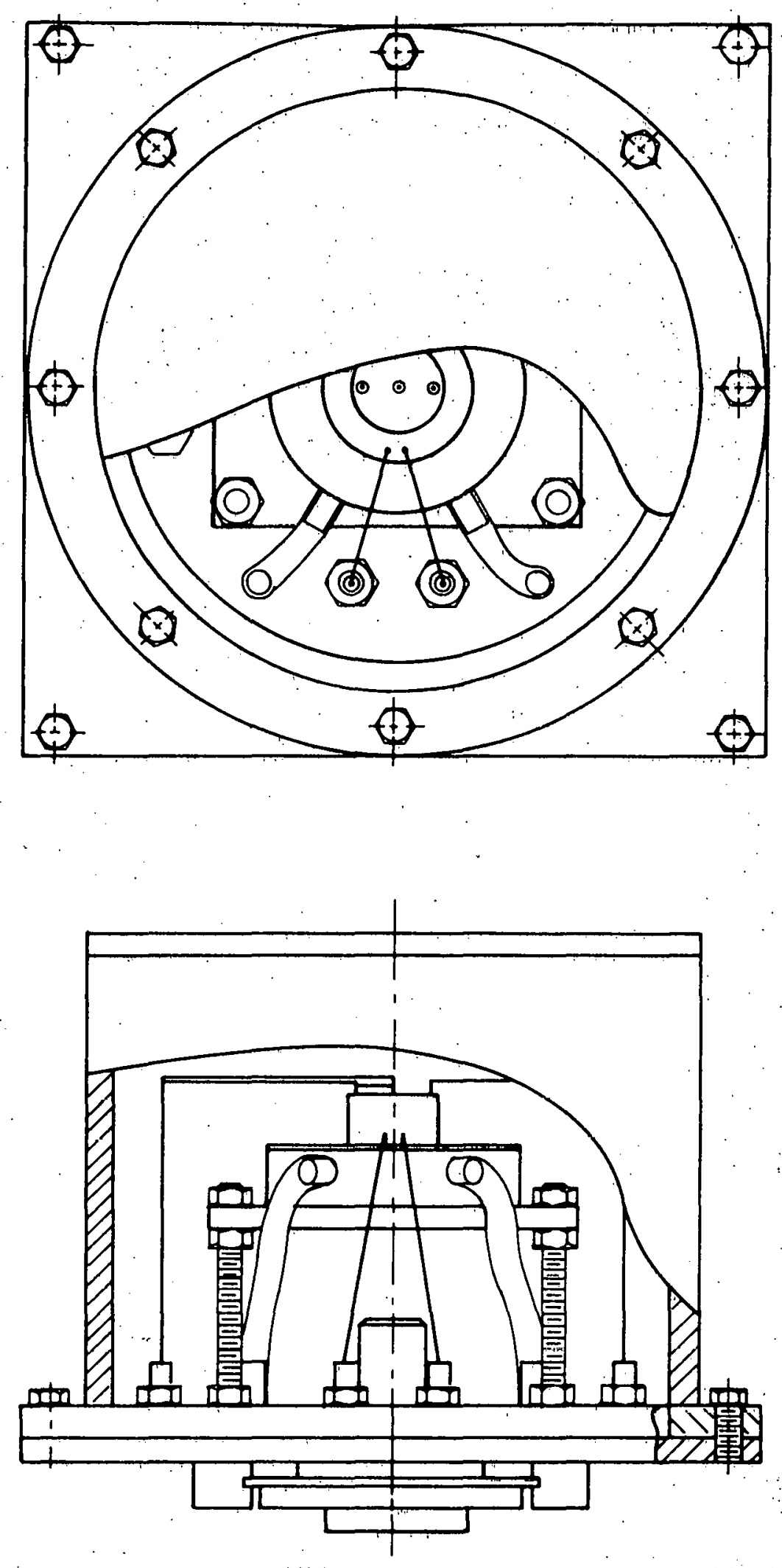

Fig. 2. Test Chamber and Sample Holder Assembly 


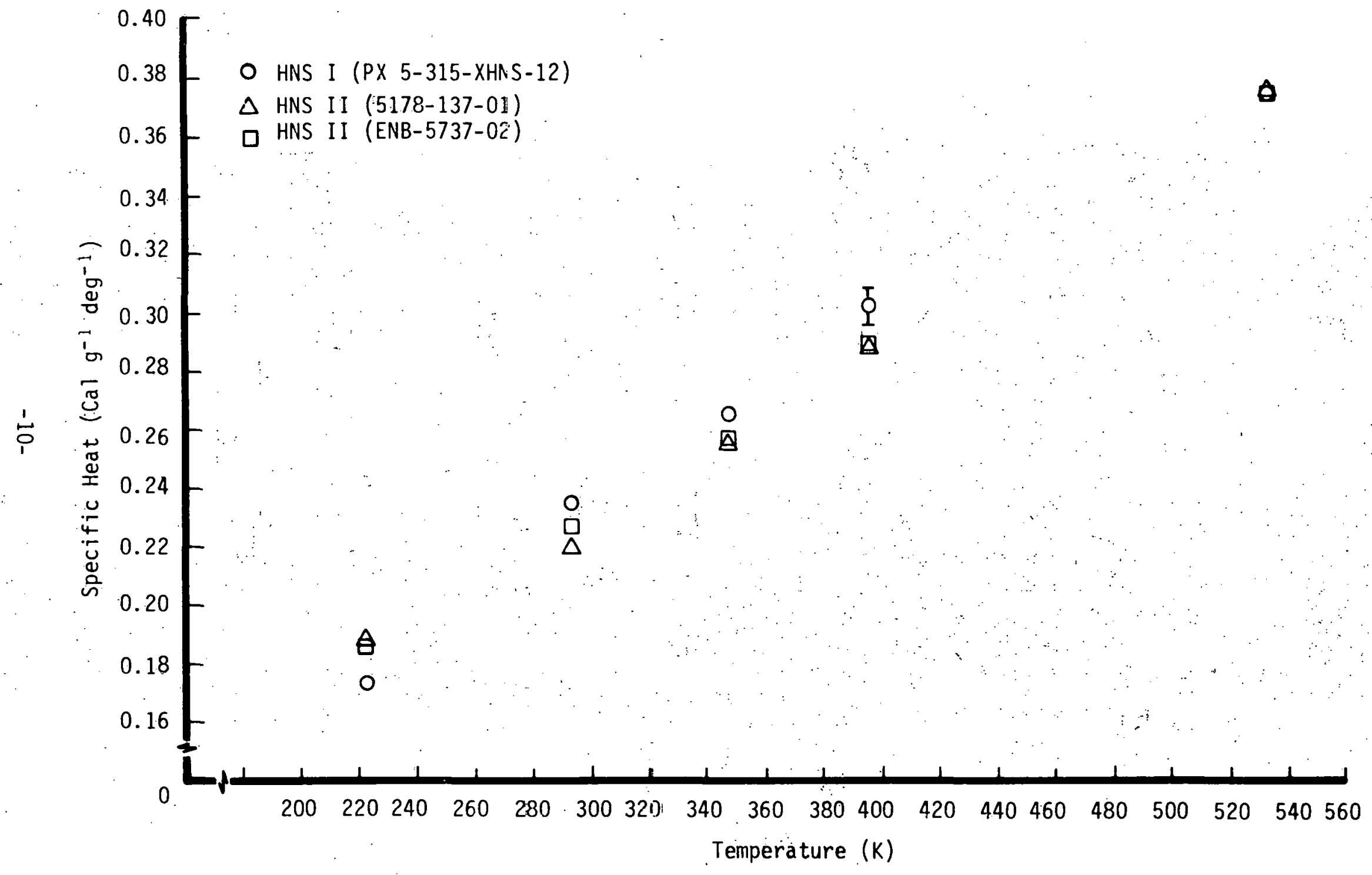

Fig. 3. Specific Heat of HNS as a Function of Absolute Temperature 


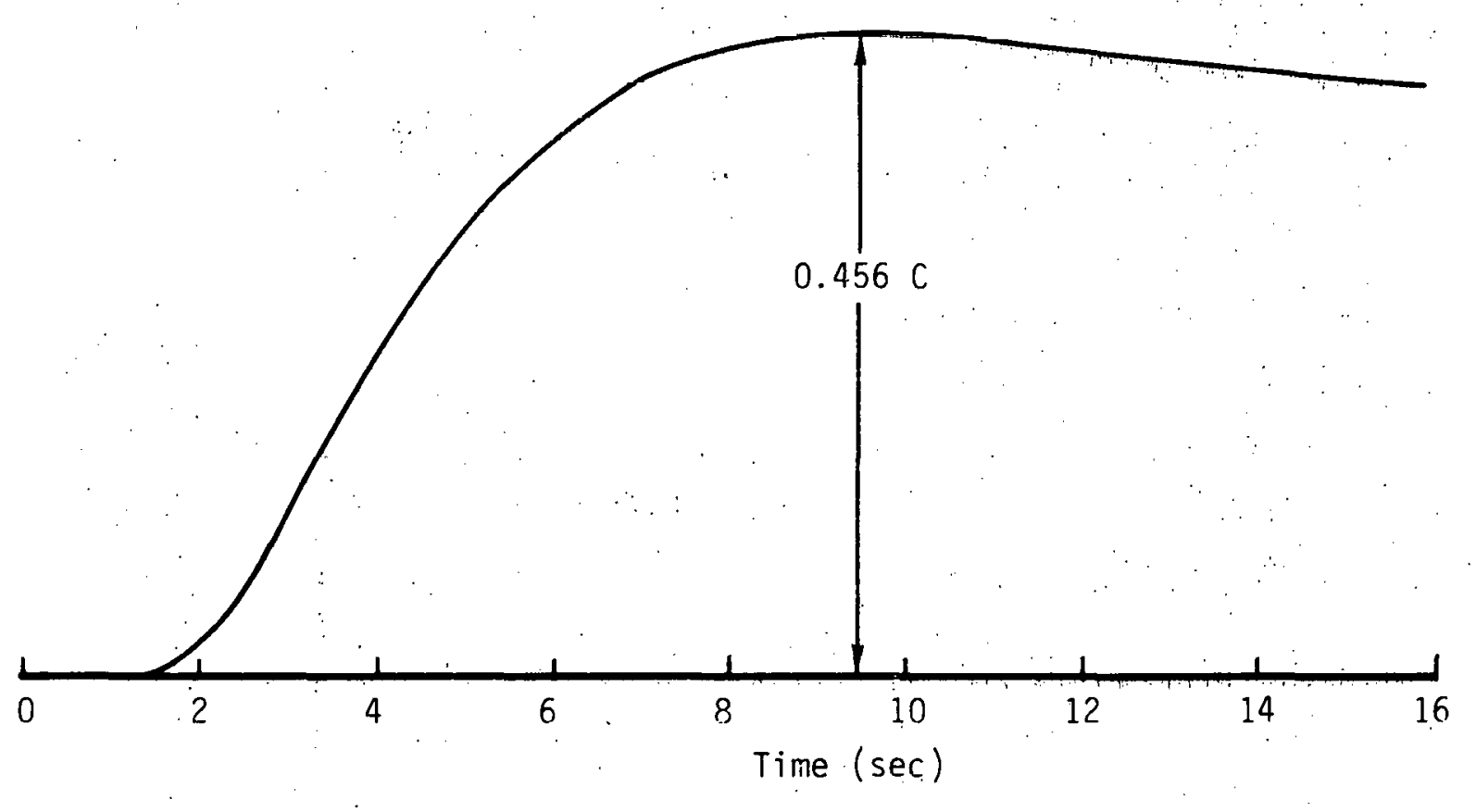

Fị. 4. Temperature-Time Curve for Rear Surface of Pellet 


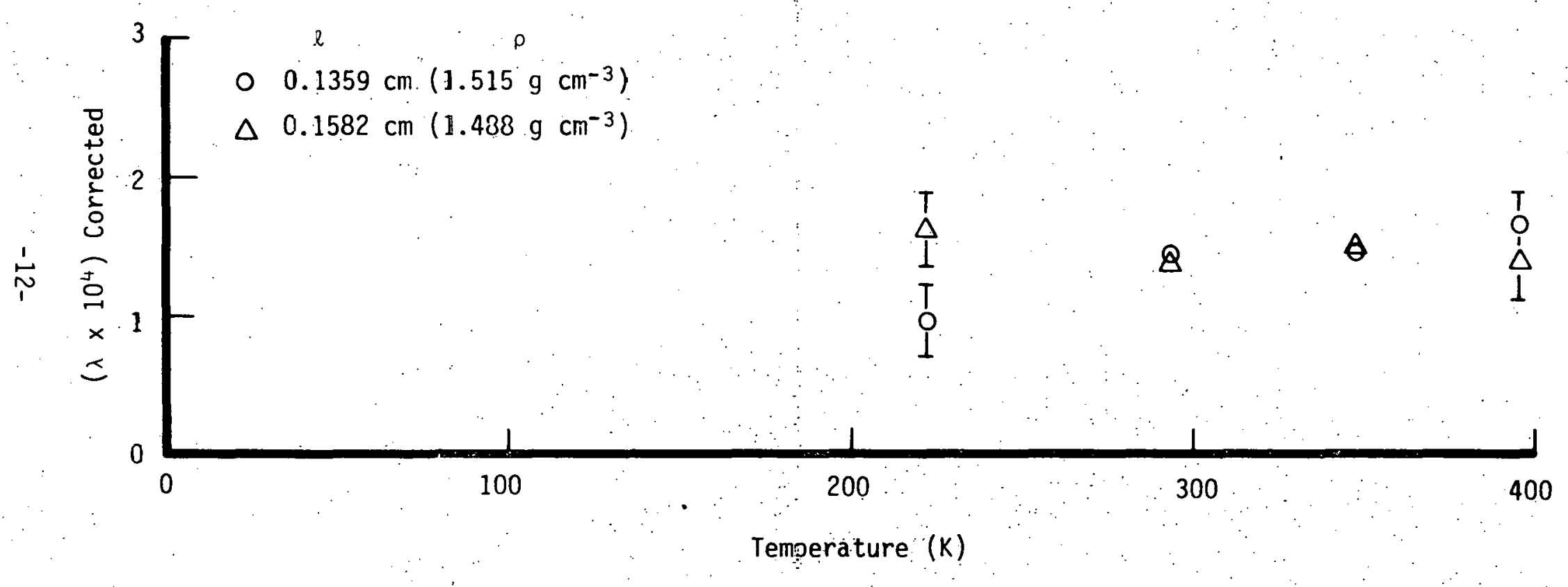

Fig. 5. Corrected Thermal Conductivity of HWS I at approximately $1.5 \mathrm{~g} \mathrm{~cm}^{-3}$. 


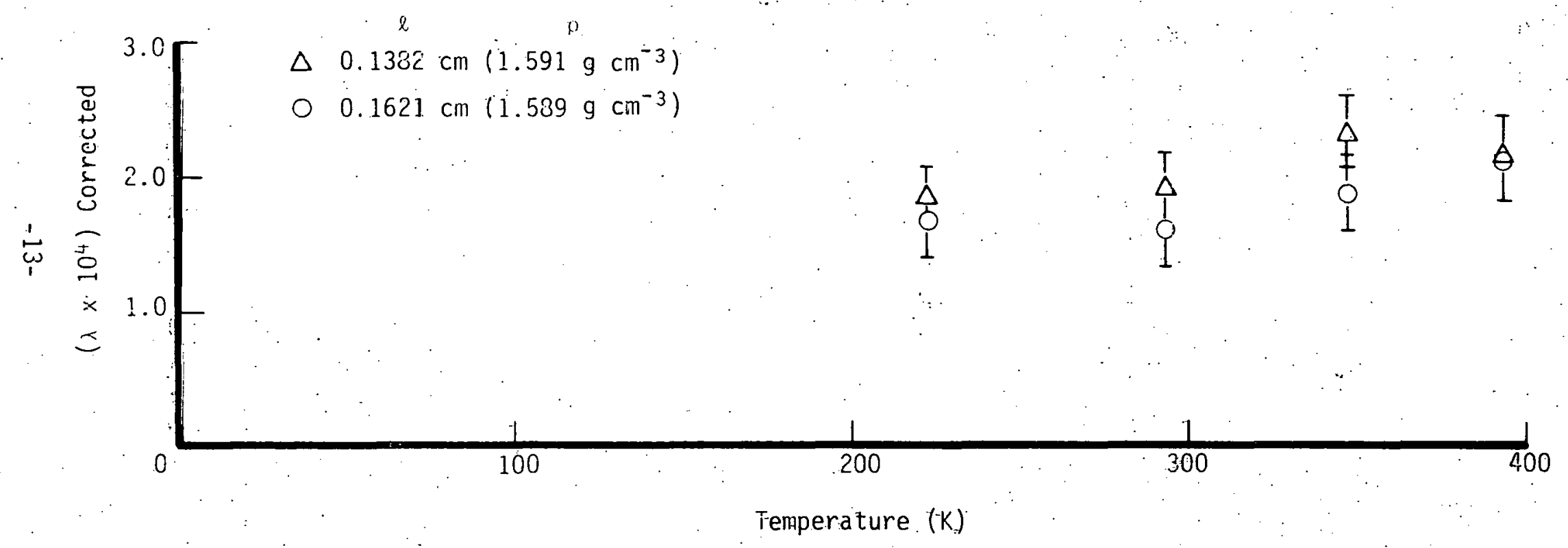

Fig. 6. Corrected Thermal Conductivity of HNS-I at approximately $1.6 \mathrm{~g} \mathrm{~cm}^{-3}$ 


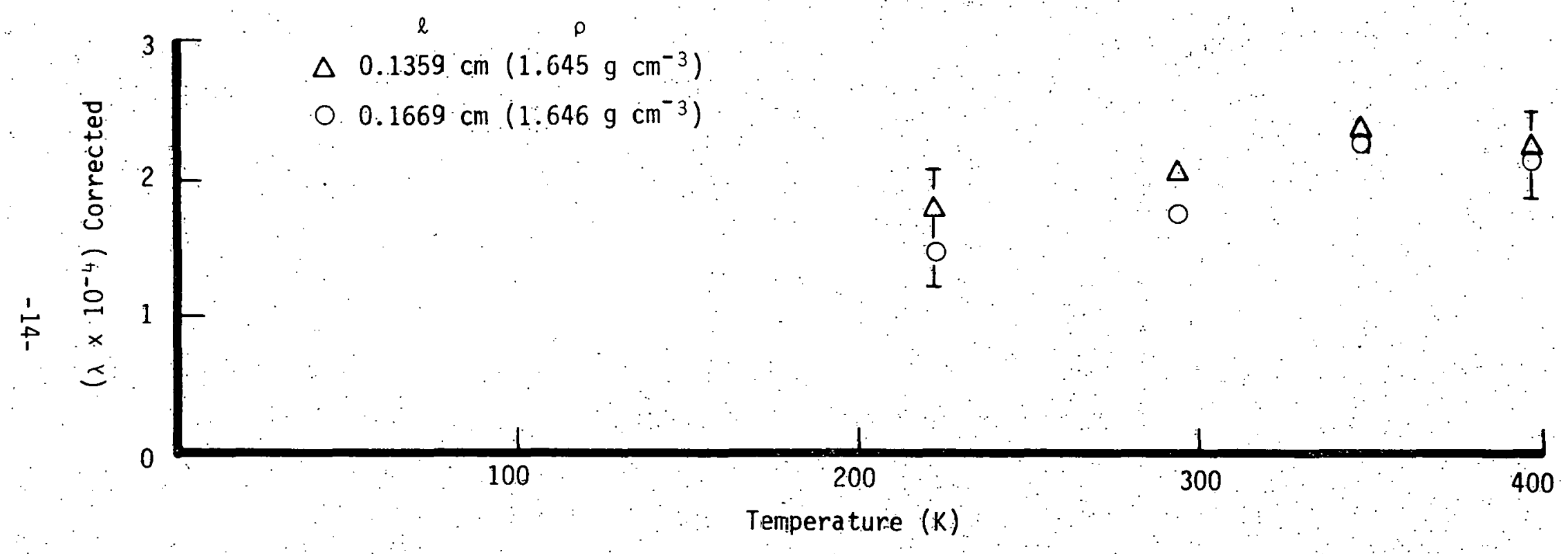

Fig. 7. Corrected Thermal Conductivity of HNS I at approximately $1.65 \mathrm{~g} \mathrm{~cm}^{-3}$ 


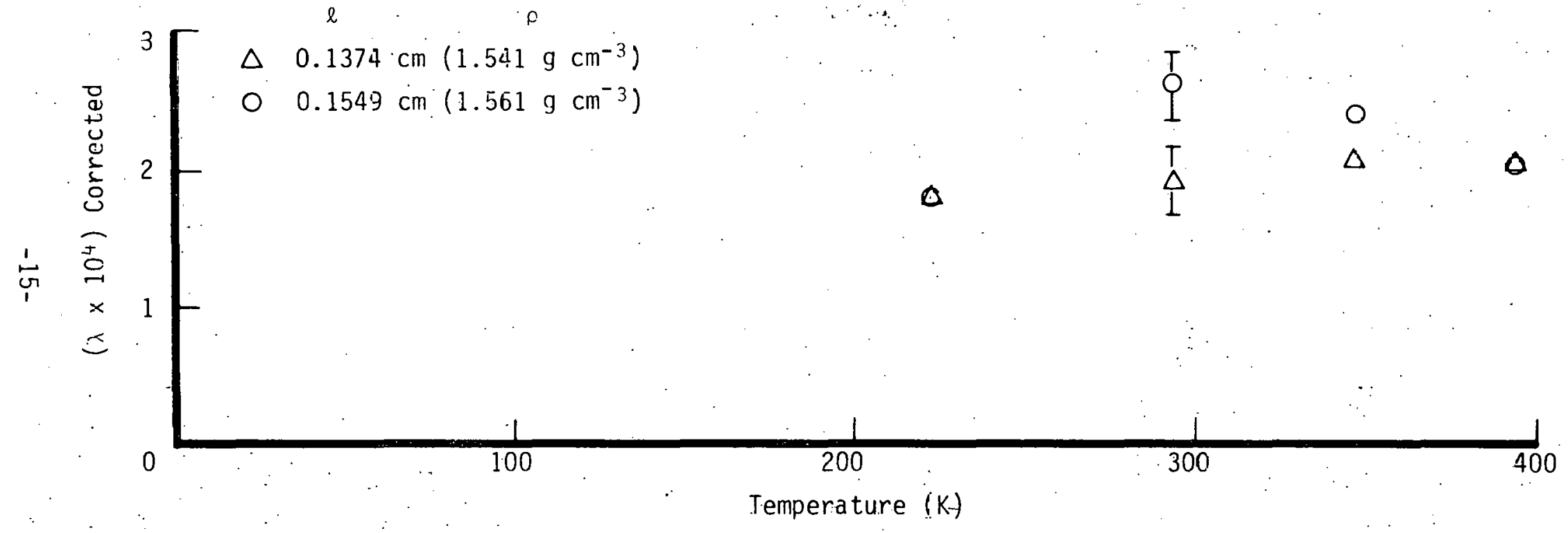

Fig. 3. Corrected Thermal Conductivity of HWS II (Paniex) at approximately $1.55 \mathrm{~g} \mathrm{~cm}^{-3}$ 


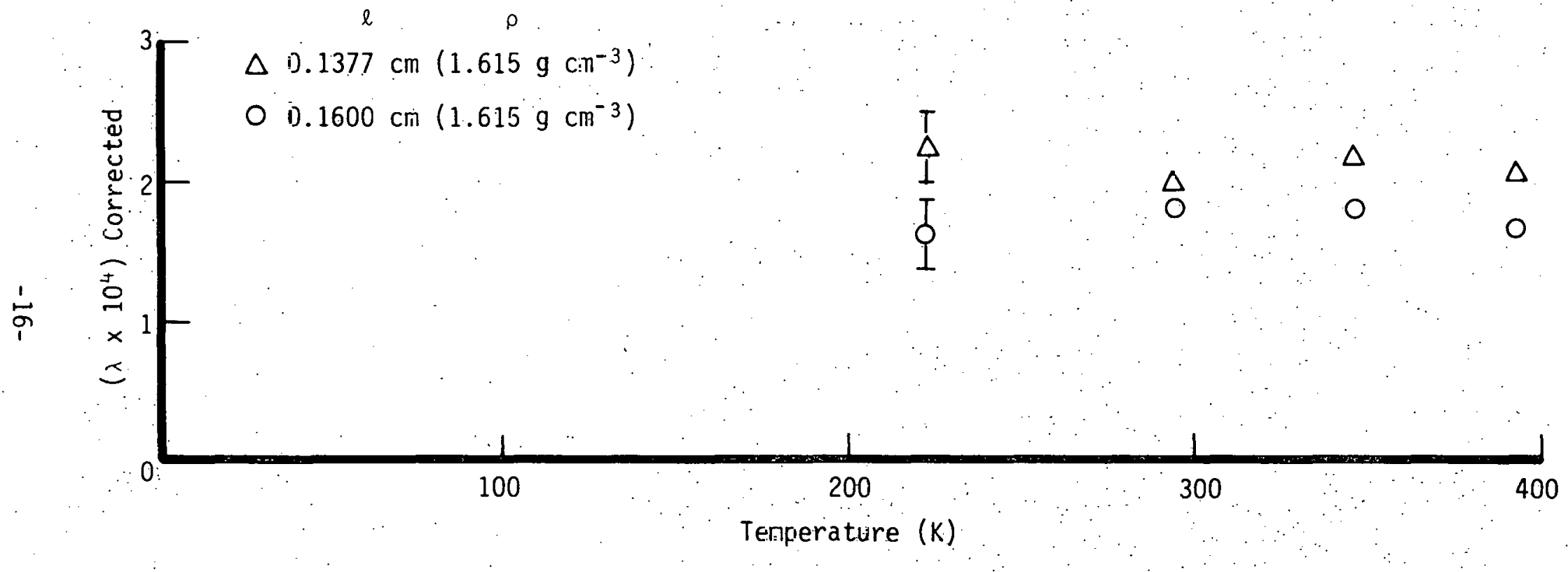

Fig. 9. Correctec Thermal Conductivity of HNS II (Pantex) at approxinictely $1.615 \mathrm{~g} \mathrm{~cm}^{-3}$ 


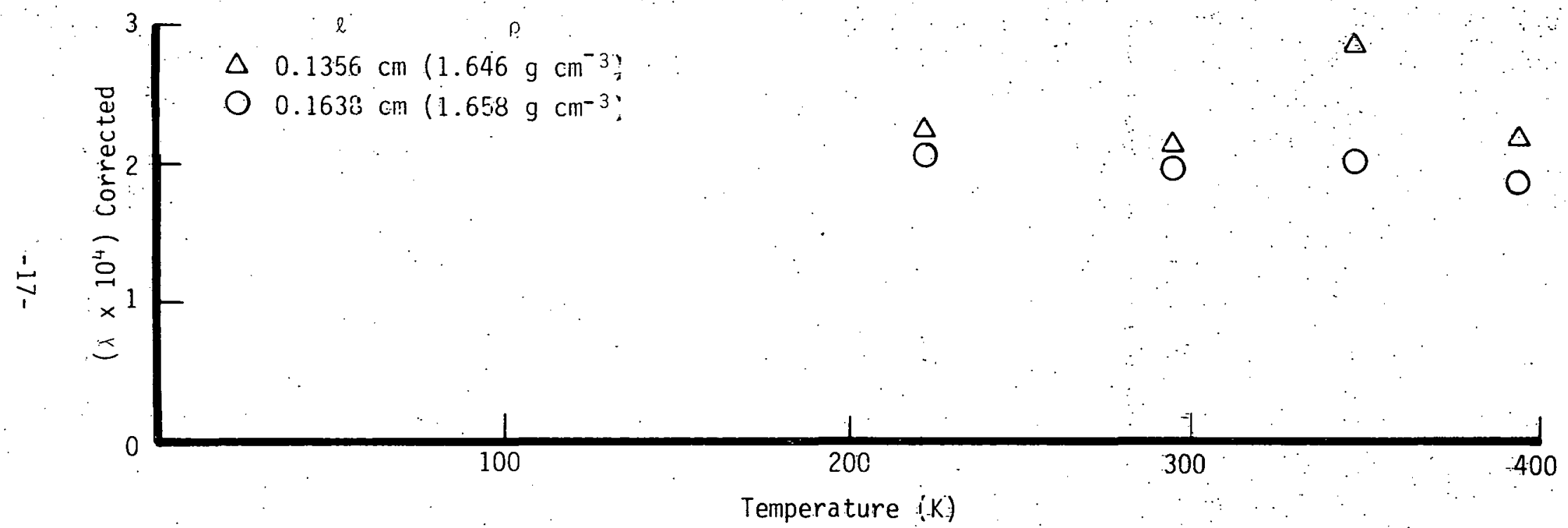

Fig. 10. Corrected Thermal Conductivity of HNS II (Pantex) at approximately $1.65 \mathrm{~g}-\mathrm{cm}^{-3}$ 


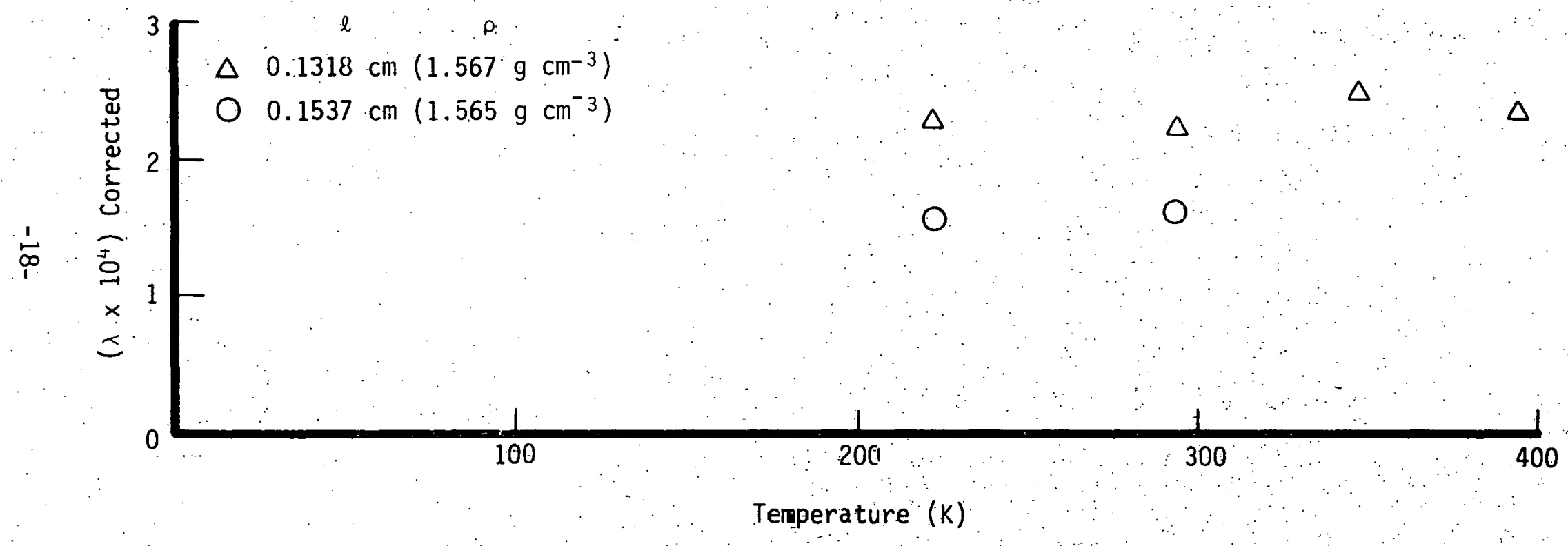

Fig. 11. Corrected Thermal Concuctivity of HNS II (Ensign Bickford) at approximately $1.56 \mathrm{~g} \mathrm{~cm}^{-3}$ 


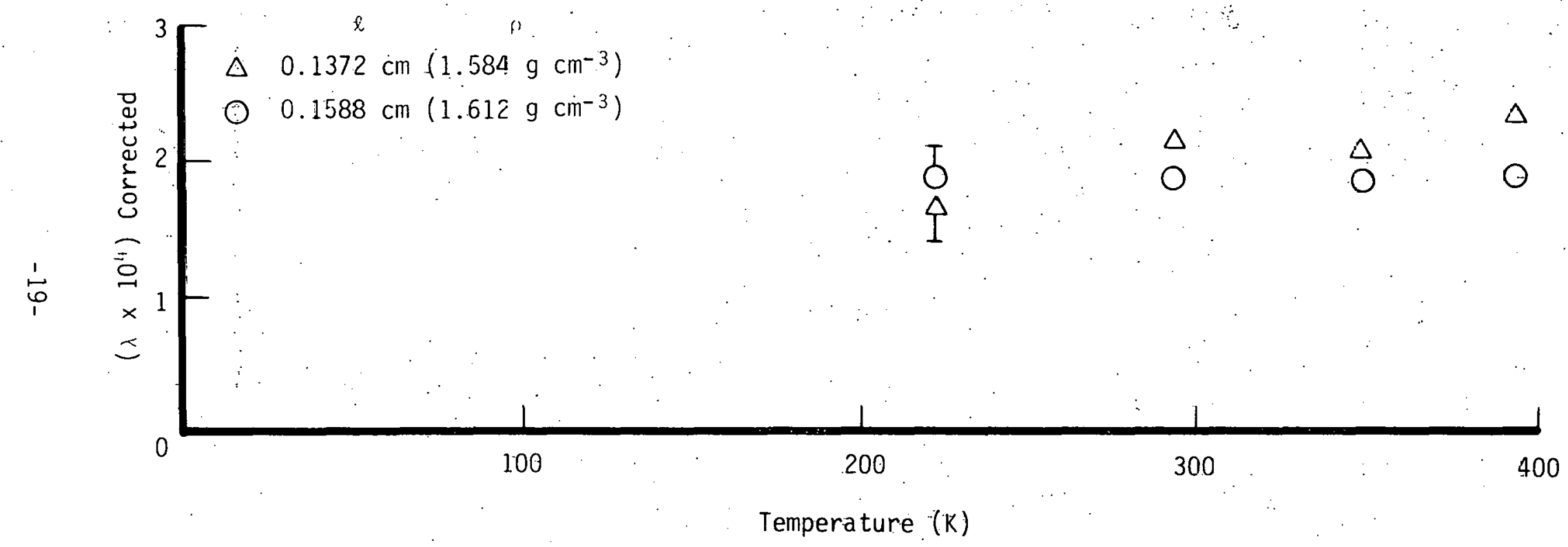

Fig. 12. Corrected Thermal Conductivity ef HNS II (Ensign Bickford) at approximate $y$ y $1.6 \mathrm{~g} \mathrm{~cm} \mathrm{~cm}^{-3}$ 


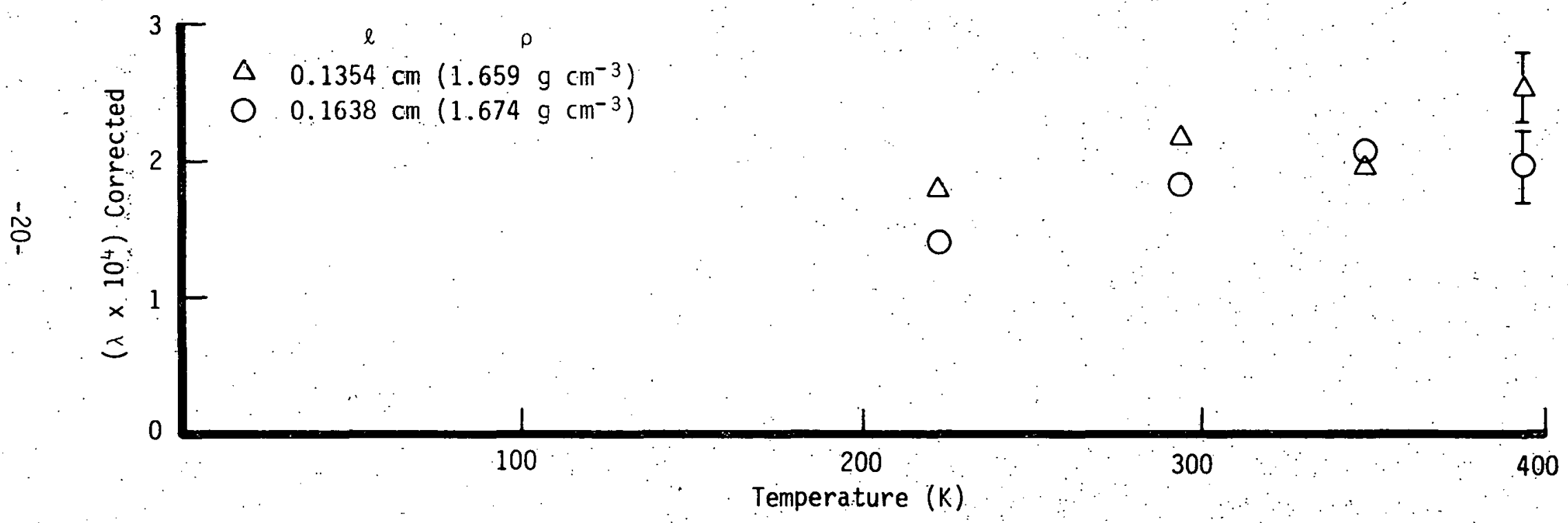

Fig. 13. Corrected Thermá ? Conductivity of HNS II (Ensign Bickford) at approximately $1.66 \mathrm{~g} \mathrm{~cm}^{-3}$ 


\section{REFERENCES}

1. W. J. Parker, et.al., U. S. Navy Radiological Defense Laboratory, USNLRDL-TR-424, May 1960.

2. R. L. Rudkin, R. J. Jenkins and W. J. Parker, Rev. Sci. Instr., 33 (1962) 21.

3. H. W. Deem and W. D. Wood, Rev. Sci. Instri, 33 (1962) 1107.

4. J. T. Schriempf, Report of NRL Progress (February 1972) 9.

5. V. I. Chistyskov, Teplofizika Vysokikh Temperatur, 11, (1973) 832 .

6. R. D. Cowan, J. Appl. Phys., 34 (1963) 926.

7. J. A. Cape and G. W. Lehman, J. Appl. Phys., 34, (1963) 1909.

8. R. C. Heckman, J.Appl. Phys., 44 (1973) 1455.

9. Thermal Analys is Newsletter, No. 3, Perkin-Elmer Corporation, Norwalk, Connecticut.

10. Raymond R. Rogers, Thermochemica Acta, 11, (1975) 131. 